\title{
Moisture content modeling and effective moisture diffusivity determination during convective solar drying of blackberry (rubus spp) and basil (Ocimum basilicum L.)
}

\author{
López-Ortiz, A. ${ }^{\text {a,b*; }}$ Gallardo-Brígido, J.C.a; Silva-Norman, A.c; Pilatowsky-Figueroa, \\ I. ; García-Valladares, O. ${ }^{\text {; }}$ Rodríguez-Ramírez, J. ${ }^{d}$ \\ ${ }^{\text {a }}$ Laboratorio de Secado Solar, Coordinación de Refrigeración y Bombas de Calor, Instituto de Energías \\ Renovables, Universidad Nacional Autónoma de México. Temixco, Morelos. México. \\ b Catedrática CONACyT. Consejo Nacional de Ciencia y Tecnología. Ciudad de México. \\ c Posgrado en Ciencias de la Sostenibilidad. Universidad Nacional Autónoma de México. \\ ${ }^{\mathrm{d}}$ Instituto Politécnico Nacional, Centro Interdisciplinario de Investigación para el Desarrollo Integral \\ Regional (CIIDIR) Unidad Oaxaca, Santa Cruz Xoxocotlán Oaxaca, México.
}

*E-mail of the corresponding author: $\underline{\text { alo@ier.unam.mx }}$

\begin{abstract}
The goal of reducing energy consumption (EC), losses and waste (FL) in the food processing is a challenges in the worldwide. The use of active solar greenhouse dryers (GHD) for EC and FL reductions has increased due to its capacity, and low operating costs. In this work the effective diffusivity (Deff) and the moisture content modeling were analized for basil (Ocimum basilicum) and blackberry pulp (Rubus rosoideae) dried in a conventional stove (CD) and an GHD coupled to an additional air solar heating system $\left(\mathrm{SCH}_{a}\right)$. The loss of water and the drying rate in food materials dehydrated in the GHD is consistent with the increment or decrement of temperature during the solar day. The $D_{\text {eff }}$ values for basil and blackberry pulp was ranged between $1.1044 \times 10^{-7}$ and $-3.9167 \times 10^{-9}$. The solar energy obtained in the GHD supplied the heating requirements. In general, the Page's model was the best fit for the drying kinetics for basil and blackberry pulp.
\end{abstract}

Keywords: Solar Collector for air heating, solar energy, variable conditions. 


\section{Introduction}

In the world, 1.3 billion tons of food loss and waste are generated each year [1]. Therefore, it is necessary to implement food conservation methods. These technologies could also allow the reduction of energy consumption.

The energy consumption for food preservation in Mexico is not fully quantified. According to SENER of Mexico, (2016), 28.9\% of the energy is used by the industrial sector in this country. The major energy consumption of the food industry is $43 \%$ and it is used for processing and distribution. Processing, drying, and curing are the most energy-intensive farm operations, due to the high costs of heating and the removal of moisture from the saturated air and the food matrix[2].

Drying is a unitary operation, that allows the water reduction from food, to extend its shelf life. Different solar drying systems have been used for food preservation, and they are classified as follows: direct, indirect, and mixed solar drying technologies[3]. Solar greenhouse dryers are classified as direct solar drying systems. They have been used for the drying of grains, fruits, and vegetables[3,4,5,6]. However, drying times are long and the product quality is poor $[7,8]$.

Solar greenhouse dryers can also be connected to an air solar heating system (SCHa). The air heating concept or preheating system was recently introduced[9]. This system was used for drying of pepper, where different air mass flows rates and the drying kinetics were analyzed. The maximum temperature inside the greenhouse dryer was $45^{\circ} \mathrm{C}$.

Moreover, there are drying predictive models, and, they derived from Fick's second law and Newton's law of cooling[7,8,9,10]. But, the study of effective diffusivity is necessary in this novel system. Therefore, the main objective of this work was to evaluate the moisture diffusivity of basil (Ocimum basilicum) and blackberry (Rubus rosoideae), which were dehydrated in a solar greenhouse dryer coupled with an additional air solar heating system.

\section{Modeling}

The mass transfer phenomenon in drying has been simplified when considering the liquid mass transportation according to Fick's second law, where the driving force is a concentration gradient.

$$
\frac{d X_{a}}{d t}=-D_{A x} \frac{d \rho X_{a}}{d x^{2}}
$$

Considering that the water movement is unidirectional, in a case of a flat plate with a constant diffusivity, the equation (1) can be expressed according to Crank \& Park[11] in the following form, 


$$
W=\frac{X_{(t)}-X_{e}}{X_{0}-X_{e}}=\frac{8}{\pi^{2}} \sum_{i=0}^{\infty} \frac{1}{(2 n+1)^{2}} e^{-\frac{\pi^{2}}{4 \cdot l^{2}}(2 n+1)^{2} D_{A x} \cdot t}
$$

Where W is the normalized moisture content. Simplifying the equation (2), the Fick's second law solution is expressed as:

$$
W=\frac{X_{(i)}-X_{e}}{X_{0}-X_{e}}=\frac{8}{\pi^{2}} e^{-\frac{\pi^{2}}{4 \cdot l_{o}^{2}} D_{A x} \cdot t}
$$

Where the diffusive coefficient $\left(D_{A x}\right)$ can be evaluated considering an effective mass transference ( $\left.\mathrm{D}_{\mathrm{eff}}\right)$.

\subsection{Empirical and semi-empirical modeling}

Semi-empirical models are calculated for specific conditions of relative moisture, temperature, and air-drying speed. In solar drying, empirical and semi-empirical models have been used on thin plane plates to describe the behavior of $\mathrm{W}$ during the process (Table 1). The adjustable parameters must be calculated for each food type and drying condition. Some models are derived from the solution of Newton's law of cooling equation and others from Fick's second law (Equation 1).

Table 1. Predictive models for $W$

\begin{tabular}{llll}
\hline Semi-empirical models & Model & Equation & Reference \\
\hline Models Resulting from & Newton & $\mathrm{W}=\exp (-\mathrm{kt})$ & {$[12]$} \\
Newton's Law of & Page & $\mathrm{W}=\exp \left(-\mathrm{kt}^{\mathrm{n}}\right)$ & {$[13]$} \\
Cooling & Modified Page & $\mathrm{W}=\exp \left(-(\mathrm{kt})^{\mathrm{n}}\right)$ & {$[7]$} \\
\hline Models Resulting from & Henderson and Pabis & $\mathrm{W}=\mathrm{a} \exp (-\mathrm{kt})$ & {$[14]$} \\
Ficks Second Law of & Logarithmic & $\mathrm{W}=\mathrm{a} \exp (-\mathrm{kt})+\mathrm{c}$ & {$[15]$} \\
Diffusion & & $\mathrm{W}=\mathrm{a} \exp (-\mathrm{kt})+\mathrm{b} \exp \left(-\mathrm{k}_{\mathrm{t}} \mathrm{t}\right)$ & {$[16]$} \\
& Two-term & $\mathrm{W}=\mathrm{a} \exp (-\mathrm{kt})+(1-\mathrm{a}) \exp \left(-\mathrm{k}_{1} \mathrm{t}\right)$ & {$[17]$} \\
& Two-term exponential & {$[18]$} \\
\hline Empirical models & Midilli and Kucuk & $\mathrm{W}=\mathrm{a} \exp \left(-\mathrm{kt} \mathrm{t}^{\mathrm{n}}\right)+\mathrm{bt}$ & {$[19]$} \\
\hline
\end{tabular}

Where $\mathrm{W}$ can be adjusted to the shown models in Table 1. In this work, adjustments were made to the Newton's, Page's, and Wang and Singh's equations.

\subsection{Statistical analysis}

The square root means deviation (RMSD) between the predicted and experimental data were evaluated with the following equation,

$$
R M S D=\sqrt{\frac{\sum_{i=1}^{i=n}\left(\mathrm{~W}_{\mathrm{Exp}, \mathrm{i}}-\mathrm{W}_{\mathrm{Th}, \mathrm{i}}\right)^{2}}{\mathrm{n}-1}}
$$


The main deviation between the experimental data and the results produced by the model were evaluated with relative error:

$$
\operatorname{Error}(\%)=\frac{100}{\mathrm{n}} * \sum_{i=1}^{i=n} \frac{\left(\mathrm{W}_{\mathrm{Exp}, \mathrm{i}}-\mathrm{W}_{\mathrm{Th}, \mathrm{i}}\right)^{2}}{\mathrm{~W}_{\mathrm{Exp}, \mathrm{i}}}
$$

The reduced chi-square value of $\left(\chi^{2}\right)$ was calculated as follows,

$$
\chi^{2}=\frac{\sum_{i=1}^{i=n}\left(\mathrm{~W}_{\mathrm{Exp}, \mathrm{i}}-\mathrm{W}_{\mathrm{Th}, \mathrm{i}}\right)^{2}}{\mathrm{n}-\mathrm{N}}
$$

where $\mathrm{W}_{\text {Exp,i }}$ represents the experimental moisture ratio, $\mathrm{W}_{\mathrm{Th}, \mathrm{i}}$ is the humidity ratio predicted by the mathematical model, $\mathrm{n}$ is the number of observations and $\mathrm{N}$ is the number of constants.

\section{Materials}

Basil (Ocimum basilicum) was obtained from a local farmer in Tequesquitengo, Morelos, Mexico, and blackberry (Rubus rosoideae) from Los Reyes, Michoacán, Mexico was used. In the basil drying case, only leaves were used. The samples were put over a perforated plastic mesh, covering a total surface of $16 \mathrm{~m}^{2}$. The blackberry was liquefied and the seeds separated. A thin layer of about $5 \pm 1 \mathrm{~mm}$ of strawberry pulp was spread over 40.4 x $26.5 \mathrm{~cm}$ trays. In this case, a drying surface of $8 \mathrm{~m}^{2}$ was used for the drying process. The results were compared with samples dried in an electric oven at $60^{\circ} \mathrm{C}$ with forced convection at $1 \mathrm{~m} / \mathrm{s}$. The weight loss was measured during the drying process.

\subsection{Description of the drying equipment}

A solar greenhouse dryer (Figs 1 and 2) was used (GHD), it was connected to an air solar heating system $\left(\mathrm{SCH}_{\mathrm{a}}\right)$. The air solar heating system was constituted by three air heating flat plate solar collectors that consist in a box with insulation, an absorber, and a glass cover. The collector dimensions are $2.10 \mathrm{~m}$ in length, $1.20 \mathrm{~m}$ in width and $0.093 \mathrm{~m}$ in thickness. The cover was made of texturized corrugated tempered glass with a thickness of $4 \mathrm{~mm}$. The $\mathrm{SCH}_{\mathrm{a}}$ was oriented to the south and inclined at an angle of $22^{\circ}$ to the horizontal plane to maximize the absorption of solar radiation during the test. For the air inlet to the GHD a radial fan (Air Technology, CFD-7-3, Mexico) was connected to the $\mathrm{SCH}_{\mathrm{a}}$. Therefore, the system can be operating with natural or forced convection (Figure 1). Two air-diffusers with honeycomb structure for air distribution in the GHD was connected in the south wall. For air moisture and air flow removal from the GHD, two air fans (SilentVent, HAE 150) was connected in the north wall. The temperature was measured using Type $T$ thermocouples (uncertainty of $\pm 1^{\circ} \mathrm{C}$ ). The solar irradiation ( $\mathrm{W} / \mathrm{m}^{2}$ ) outside and inside of the GHD was measured using two pyranometers (Kipp \& Zonen, CMP6, Netherlands). The air humidity (HR\%) was measured using sensors (AOSONG, DHT22, uncertainty of $\pm 2 \%$ ). The inlet and outlet air velocity was measured using an anemometer (Extech Instruments, SDL 350). 
The tests were carry out in Temixco, Morelos, Mexico $\left(18.85^{\circ}\right.$ latitute North and $-99.2333^{\circ}$ longitude East and an altitude of $1219 \mathrm{~m}$ above sea level). The experiments were done in the months of March, May, and June 2017. In the tests with forced convection, an air velocity of $0.58 \mathrm{~m} / \mathrm{s} \pm 0.12 \mathrm{~m} / \mathrm{s}$ was used and a maximum irradiance of $806 \mathrm{~W} / \mathrm{m}^{2}$ was recorded.

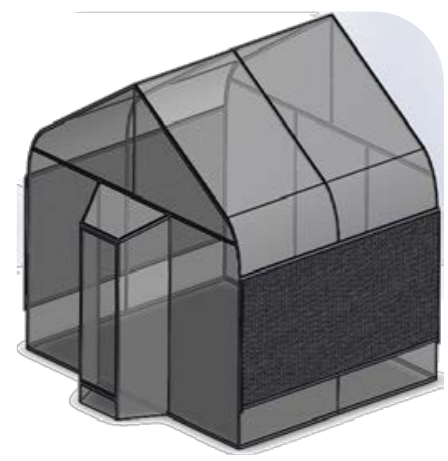

Fig. 1 Solar greenhouse dryer (GHD). Outside view. view without the plastic cover and with air heaters.

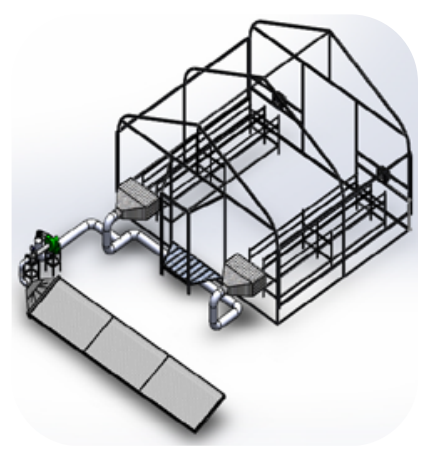

Fig. 2 Solar greenhouse dryer (GHD),

A software for data acquisition was used during the test. The data collecting was done every $30 \mathrm{~s}$.

\section{Results}

The maximal average drying temperature into the greenhouse was $44.02 \pm 1.90{ }^{\circ} \mathrm{C}$ with a maximal average solar irradiance of $806.34 \pm 6.12 \mathrm{~W} / \mathrm{m}^{2}$ and inlet average air velocity of $0.58 \pm 0.12 \mathrm{~m} / \mathrm{s}$ of the greenhouse. In figure 2 , the drying kinetics of dehydrated basil and blackberry are observed. In the greenhouse (GHD) and electrical stove (CD), the drying kinetics are according to the typical behaviour of drying processes. The initial moisture content of basil was $7.021 \pm 0.001 \mathrm{~kg}_{\mathrm{w}} / \mathrm{kg}_{\mathrm{ds}}$ and for the blackberry was $9.470 \pm 0.422$ $\mathrm{kg}_{\mathrm{w}} / \mathrm{kg}_{\mathrm{ds}}$. For the basil (Figure 2a.), the drying time in the GHD was 330 minutes and in the CD was 123.8 minutes. Figure $2 \mathrm{~b}$ shows the blackberry pulp drying kinetics, in the stove the drying time was 480 minutes. But in the GHD, the dehydration was prolonged until a second day (960 minutes).

The $\ln (\mathrm{W})$ (figure 3) was used to get the linearization of equation 3[20], considering the decreasing drying rate interval. With $\mathrm{CD}$, the slope is less than with GHD, due to the mean temperature of each system (60 and $43.52^{\circ} \mathrm{C}$ for CD and GHD respectively).

The $\mathrm{D}_{\text {eff }}$ results with the slopes of the lines in fig. 3 shows a difference in the values obtained (Table 2). It can be observed that the $\mathrm{D}_{\text {eff }}$ values for blackberry pulp are greater than the basil; therefore, the mass transference is major in the blackberry pulp. Furthermore, the $D_{\text {eff }}$ values 
for CD indicate that a higher mass flux can be obtained. Nevertheless, the energy-saving with GHD is greater than with CD, and a good dried product was obtained in both technologies.

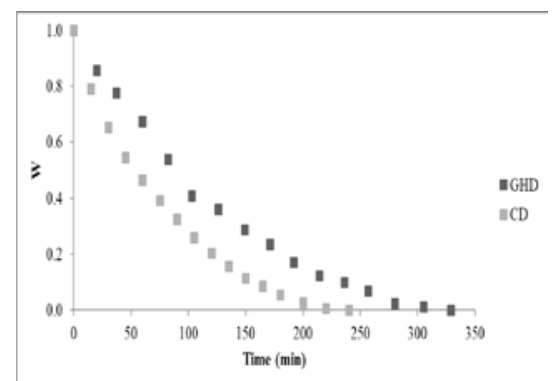

(a)

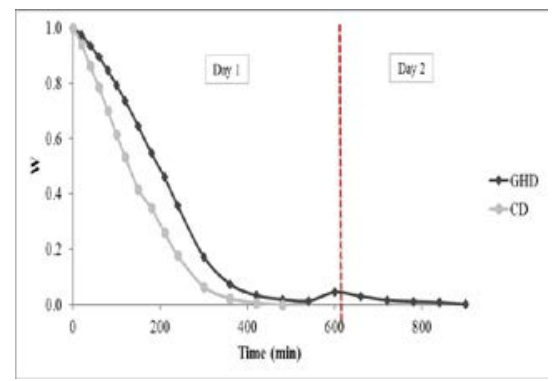

(b)

Fig. 2 Basil (a) and blackberry (b) drying kinetics, using greenhouse dehydrated (GHD) and electrical stove (CD).

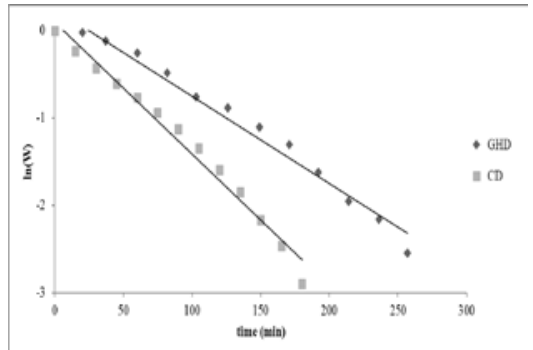

(a)

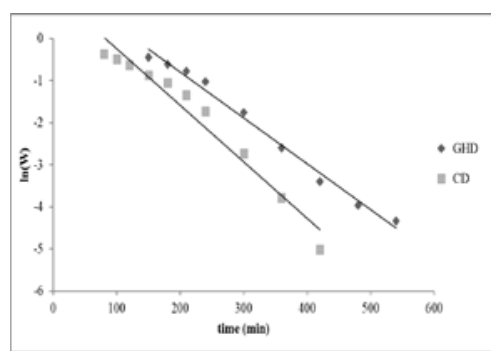

(b)

Fig. 3 In (W) vs drying times for (a) basil, and (b) blackberry pulp.

Table 2. Effective diffusivity values

\begin{tabular}{ccc}
\hline & $\mathbf{R}^{\mathbf{2}}$ & $\mathbf{D}_{\text {eff }}\left(\mathbf{m}^{2} / \mathbf{s}\right)$ \\
\hline CD, Blackberry & & \\
GHD, Blackberry & 0.961 & $-1.3577 \mathrm{E}-07$ \\
CD, Basil & 0.981 & $-1.1044 \mathrm{E}-07$ \\
GHD, Basil & 0.977 & $-2.5938 \mathrm{E}-09$ \\
\hline
\end{tabular}

Table 3 shows adjustable parameters and the values for Newton's, Page's, and Wang and Singh's models for the blackberry and basil experiments. In the basil-GHD, the best adjustment with Wang and Singh's equation was found, followed for Page's model. In the basil-CD, blackberry-GHD and blackberry-CD the best was with Page's, it was due to a minor value of \%error, $\chi^{2}$ and RMSD and major value of $\mathrm{R}^{2}$. 
Table 3 Adjustable parameters for different mathematical models

\begin{tabular}{|c|c|c|c|c|}
\hline & Parameters & Newton & Page & Wang and Singh \\
\hline \multirow{6}{*}{$\begin{array}{l}\text { Basil } \\
\text { GHD }\end{array}$} & $n$ & 0.0000 & 1.2331 & -0.0063 \\
\hline & $\mathrm{k}$ & 0.0086 & 0.0027 & 0.0000 \\
\hline & $\mathrm{R}^{2}$ & 0.9831 & 0.9954 & 0.9966 \\
\hline & RMSD & 0.6551 & 0.3410 & 0.2957 \\
\hline & $X^{2}$ & 0.0018 & 0.0005 & 0.0004 \\
\hline & \%error & 3.1998 & 0.7705 & 0.1517 \\
\hline \multirow{6}{*}{$\begin{array}{c}\text { Basil } \\
\text { CD }\end{array}$} & $\mathrm{N}$ & 0.0000 & 1.0439 & -0.0096 \\
\hline & K & -0.0136 & 0.0112 & 0.0000 \\
\hline & $\mathrm{R}^{2}$ & 0.9926 & 0.9932 & 0.9820 \\
\hline & RMSD & 0.4033 & 0.3858 & 1.5941 \\
\hline & $X^{2}$ & 0.0007 & 0.0007 & 0.0113 \\
\hline & \%error & 1.8917 & 1.4044 & 30.1498 \\
\hline \multirow{6}{*}{$\begin{array}{c}\text { Blackberry } \\
\text { GHD }\end{array}$} & $\mathrm{N}$ & 0.0000 & 1.7241 & -0.0030 \\
\hline & $\mathrm{K}$ & -0.0042 & 0.0001 & 0.0000 \\
\hline & $\mathrm{R}^{2}$ & 0.9476 & 0.9971 & 0.9724 \\
\hline & RMSD & 2.0173 & 0.1802 & 18.1547 \\
\hline & $X^{2}$ & 0.0080 & 0.0001 & 0.6824 \\
\hline & \%error & 13.334 & 0.8703 & 10509 \\
\hline \multirow{6}{*}{$\begin{array}{c}\text { Blackberry } \\
\text { CD }\end{array}$} & $\mathrm{N}$ & 0.0000 & 1.4323 & -0.0046 \\
\hline & $\mathrm{K}$ & -0.0060 & 0.0007 & 0.0000 \\
\hline & $\mathrm{R}^{2}$ & 0.9657 & 0.9982 & 0.9959 \\
\hline & RMSD & 0.9548 & 0.2213 & 6.4654 \\
\hline & $X^{2}$ & 0.0043 & 0.0003 & 0.2144 \\
\hline & \%error & 9.0764 & 0.4720 & 811.31 \\
\hline
\end{tabular}

\section{Conclusions}

The loss of water and the drying rate in food materials dehydrated in the greenhouse dryer (GHD) is consistent with the increment or decrement of temperature during the solar day. The $\mathrm{D}_{\text {eff }}$ values for basil and blackberry pulp was ranged between $1.1044 \times 10^{-7}$ and $3.9167 \times 10^{-9}$. The $D_{\text {eff }}$ values for CD was higher than for GHD, and in both technologies, a good dried product was obtained. In GHD the sun supplied the heating requirements for free. In general, the Page's model was the best fit for the drying kinetics for basil and blackberry pulp. 


\section{Nomenclature}

$\begin{array}{ll}\mathrm{D}_{\mathrm{Ax}} & \text { Moisture diffusivity } \\ \mathrm{D}_{\text {eff }} & \text { Effective moisture diffusivity } \\ \mathrm{l} & \text { sample thickness } \\ \mathrm{N} & \text { Number of constants } \\ \mathrm{n} & \text { Number of observations } \\ \mathrm{t} & \text { Time } \\ \mathrm{T} & \text { Temperature } \\ \mathrm{X} & \text { Moisture content } \\ \mathrm{W} & \text { Dimensionless moisture content }\end{array}$

$$
\begin{aligned}
& \mathrm{s} / \mathrm{m}^{2} \\
& \mathrm{~S} / \mathrm{m}^{2} \\
& \mathrm{M}
\end{aligned}
$$$$
\mathrm{kg} / \mathrm{m}^{3}
$$

Subscripts

$\begin{array}{ll}\rho & \text { density } \\ \pi & \text { pi constant } \\ & \\ \text { e } & \text { equilibrium } \\ \text { exp } & \text { experimental } \\ \text { o } & \text { initial } \\ \text { Th } & \text { theoretical }\end{array}$

\section{References}

initial

[1] Gustavsson, J. Global Food Losses and Food Waste. Rome : FAO, 2011.

[2] Initiatives by Member States and international organizations are being undertaken to create an enabling environment at all levels for the . s.l. : FAO, 2011.

[3] Prakash, O. y Kumar, A. Solar green house drying: A review. Renewable and Sustainable Energy Reviews, 2014, 29, 905-910.

[4] Sethi, V.P. y Arora, S. Improvement in green house solar drying using inclined north wall reflection.. SolarEnergy, 2009, 83, 1472-1484.

[5] Rathore, N.S. y Panwar, N.L. Experimental studies on hemi cylindrical walk-in type solar tunnel dryer for grape drying. Applied Energy, 2010, 87 (8), 2764-2767.

[6] Janjai, S., y otros. A large-scale solar greenhouse dryer using polycarbonate cover: Modeling and testing in a tropical environment of Lao People’s Democratic Republic. Renewable Energy, 2011, 36, 1053-1062.

[7] Diamante, L.M. y Munro, P.A. Mathematical modelling of the thin layer solar drying of sweet potato slices. Solar Energy, 1993, 51 (4), 271-276.

[8] Sonmete, M.H., y otros. Mathematical modeling of thin layer drying of carrot slices by forced convection. Food Measurement and Characterization, 2017, 11, 629.

[9] Azaizia, Z., y otros. Investigation of a new solar greenhouse drying system for peppers. International Journal of hydrogen energy, 2017, 42, 8818-8826.

[10] Gulcimen, F., Karakaya, H. y Durmus, A. Drying of sweet basil with solar air collectors. Renewable Energy, 2016, 93, 77-86.

[11] Crank, J. y Park, G.S. Diffusion in Polymers. New York : Academic Press, 1968.

[12] Mujumdar, A.S. Handbook of Industrial Drying. New York : Marcel Dekker, 1987.

[13] Page, G.P. Factors Influencing the Maximum Rates of Air Drying Shelled Corn in Thin Layers. Lafayette, IN, : (Unpublished masterthesis), Purdue University, USA, 1949.

[14] Henderson, S. y Pabis, S. Grain drying theory: temperature effects on drying coefficient., J. Agric. Eng. Res., 1961, 6, 169-174.

[15] Singh, S, y otros. Drying and rehydration characteristics of water chestnut (Trapa natans) as a function of drying air temperature. Journal of Food Engineering, 2008, 87, 213-221.

[16] Madamba, P.S., Driscoll, R.H. y Buckle, K.A. The thin layer drying characteristics of garlic slices. J. Food Eng., 1996, 29, 75-97.

[17] Henderson, S. M. Progress in developing the thin layer drying equation. Transactions of American Society of Agricultural Engineers, 1974, 17, 1167-1172.

[18] Midilli, A., Kucuk, H. y Yapar, Z. A new model for single layer drying. Dry. Technol., 2002, 20, 1503-1513.

[19] Wang, C.Y. y Singh, R.P. A Single Layer Drying Equation for Rough Rice. American Society of Agricultural Engineers, ASAE Paper. St. Joseph. MI: American Society. Agri. Eng. 1978, 78, 3001.

[20] Tütüncü, M.A.; Labuza, T. P. Effect of Geometry on the Effective Moisture Transfer Diffusion Coefficient. J. Food Engineering, 1996, 30, 433-447. 